Original Paper

\title{
Membangun Kelompok Mahasiswa Peduli Lingkungan Melalui Penanaman Mangrove Pencegah Banjir Rob Jakarta
}

\author{
Deni Nasir Ahmad ${ }^{1}$ \\ ${ }^{1}$ Fakultas MIPA, Universitas Indraprasta PGRI, Indonesia
}

DOI: $10.29303 /$ jpmpi.v2i1.331

Sitasi: Ahmad, D. N. (2019). Membangun Kelompok Mahasiswa Peduli Lingkungan Melalui Penanaman Mangrove Pencegah Banjir Rob Jakarta. Jurnal Pengabdian Magister Pendidikan IPA (JPMPI). (2) 1. pp. 49-53

*Corresponding Author: Deni Nasir Ahmad, Fakultas MIPA, Universitas Indraprasta PGRI, Indonesia;

Email:

deninasirahmad@gmail.com

\begin{abstract}
The purpose of community service activities is to provide knowledge and direct experience to students about the effects of tidal floods and improve the environment affected by tidal flooding through mangrove or mangrove replanting activities on vacant land around the coast or coastline. The method used is field recovery and community service where the activity is divided into several activities, including: a. the introduction of mangroves and how they are planted and how they grow and develop. b. presentation of material about tides or tides in the Jakarta sea that entered the Jakarta coastline area, the impact and problems if open land around the coast is gone. c. open land planting activities around Pantai Indah Kapuk-Muara Angke, North Jakarta. The results of the activities are a. Presentation of Material Regarding Mangrove Plants and Jakarta Sea Tides. b. mangrove planting in open fields. Summary of activities are a. that mangrove land in the Jakarta area, especially in the Pantai Indah Kapuk-Muara Angke region, North Jakarta has experienced a narrowing which resulted in the area of catchment and retaining sea tides or Jakarta has experienced a slight function. b. With the existence of field recovery activities and community service, students are expected to get direct experience and be able to solve problems that occur in the surrounding environment. c. The function of mangrove land is very important for the preservation and diversity of swamps or mangrove land.
\end{abstract}

Keywords: Mangrove Plants; Rob Jakarta; Environmental Concern.

\section{Pendahuluan}

Rob merupakan naiknya atau pasangnya air laur yang masuk kedalam permukaan atau dataran sekitar pantai. Di Indonesia yang terdiri dari dataran dan banyaknya lautan memungkinkan seringnya banjir rob pada wilayah-wilayah pesisir pantai atau tepian pantai khususnya pada wilayah Ibu Kota DKI Jakarta. Banjir rob sering diterima oleh masyarakat disekitar pantai DKI Jakarta Khususnya wilayah Jakarta utara. Banjir rob menggenangi kawasan pantai Mutiara pluit, juga menyasar kawasan rentan langganan terdampak banjir rob seperti Marunda Cilincing, Pademangan, Muara Baru, Muara Angke, Kapuk dan Kamal Muara. Jakarta tidak lagi memiliki pantai publik gratis (hakikatnya pantai andalan milik publik) dan hanya menyisakan sedikit lahan konservasi hutan mangrove/bakau. Hutan mangrove dimaksud ada di dua titik area, area pertama kawasan barat di hilir sungai muara angke yang dikelola oleh Suaka Margasatwa BKSDA dan kedua kawasan timur di Marunda Cilincing (Ubaidillah, 2010).

Dari keterangan tersebut menjelaskan bahwa Jakarta rentan terhadap pasang naik air laur kemungkinan besar terjadi karena berkurangnya hutan mangrove/bakau di wilayah Jakarta. Selain hal tersebut menurut BPBD DKI Jakarta menyebutkan bahwa terjadinya banjir rob dipengaruhi oleh banyak faktor, diantaranya: 1 . Adanya fenomena iklim global yang ditandai dengan peningkatan temperatur rata-rata bumi dari tahun ke tahun. 2. Curah hujan tinggi, aliran saluran dan fungsi tanggul yang tidak maksimal. 3. Land subsidence kejadian naiknya muka laut dan penurunan muka tanah. 4. Pengaruh tinggirendahnya pasang surut air laut yang terjadi oleh gaya gravitasi. 5. Faktor-faktor atau eksternal force 
seperti dorongan air, angin atau swell (gelombang yang terjadi dari jarak jauh). 6. Badai yang merupakan fenomena alam yang sering terjadi di laut

(https://bpbd.jakarta.go.id/education/detail/109).

Hal ini terlihat jelas bahwa faktor yang mempengaruhi naiknya atau pasangnya air laut Jakarta dipengaruhi oleh banyak faktor salah satunya berkaitan dengan berkurangnya daerah resapan air atau hutan mangrove atau bakau. Oleh karenanya diperlukan suatu tindakan perbaikan atau penambahan wilayah hutan bakau di sekitar tepian laut Jakarta.

Berdasarkan hasil penelitian Sauda (2019) klasifikasi kerentanan bencana di desa yang terkena banjir rob di Kabupaten Pekalongan dibagi menjadi tiga kelas kerentanan, yaitu bahwa kelas kerentanan rendah, sedang, dan tinggi. Kerentanan lingkungan yang didapatkan dari hasil analisis memiliki tingkat kerentanan rendah sebanyak 10 desa dengan persentase $100 \%$. Hal ini menunjukkan bahwa semua desa tersebut mempunyai nilai kerentanan lingkungan yang rendah. Hal ini disebabkan karena rendahnya parameter kerentanan lingkungan yang ada di wilayah tersebut. Selanjutnya hasil penelitian Prawira (2014) menjelaskan factor-faktor yang mempengaruhi tingkat kerentanan banjir rob di Kawasan Pantai Utara Surabaya adalah kepadatan bangunan yang tinggi, kondisi jaringan jalan yang tergenang banjir rob, kurang optimalnya kondisi saluran drainase, permukiman penduduk berada di dataran rendah, fasilitas umum yang tergenang banjir rob, kepadatan penduduk yang tinggi, menurunnya pendapatan masyarakat pada sektor rentan, berkurangnya kawasan resapan air, berkurangnya kawasan hutan mangrove, permukiman penduduk berada di dekat sungai, kawasan terbangun berada di lahan rawa. Hasil penelitian tersebut menjelaskan bahwa permasalahan rob pada masing-masing daerah disebabkan oleh kerentanan yang dimiliki suatu daerah terhadap penyelesaian dampak yang akan ditimbulkan. Oleh karenanya perlu ada perhatian khusus terhadap penanganan banjir rob ini, kemungkinan salah satunya mengembalikan lahan bakau atau lahan mangrove sebagai wilayah terbuka dalam menerima rob air laut yang akan masuk kedalam wilayah pesisir pantai atau sekitar garis pantai khususnya di wilayah DKI Jakarta.

Permasalahan tersebut merupakan salah satu alasan dilakukan pengabdian masyarakat dalam menyelesaikan permasalahan kepada mahasiwa mengenai banjir rob dan pencegahan serta penyelesaian apabila terkena banjir rob pada wilayah kawasan tempat tinggal khususnya diwilayah Ibu Kota DKI Jakarta. Dari hasil penelitian Nasution (2018) menjelaskan bahwa peranan mahasiswa berupa pengetahuan dan penyelesaian masalah banjir rob adalah sebagai berikut : a. Persentase banyaknya mahasiswa yang memahami pengertian rob masuk dalam kategori tinggi $(73,38 \%)$. b. Pengetahuan mahasiswa dalam hal penyebab rob tergolong bervariasi. c. Pengetahuan mahasiswa mengenai dampak dan upaya meminimalisasi tergolong tepat yakni terdapat 2 pola berpikir yaitu pertama adalah pola dimana responden berpikir bagaimana agar tidak terjadi rob lagi. Jawaban yang diberikan responden pada pola ini adalah dengan membangun tanggul dan menanam bakau sebagai penahan agar rob tidak terjadi. Kedua yang ditemui adalah pola dimana responden berpikir bagaimana agar rob tidak mengganggu kehidupan mereka sendiri, yaitu dengan meninggikan pondasi rumah dan mengoptimalkan selokan di sekitar rumah.

Perlunya dilakukan kegiatan pengabdian masyarakat dan perkuliahan lapangan dengan tujuan dari kegiatan ini memberikan pengetahuan dan pengalaman langsung kepada mahasiswa mengenai dampak banjir rob dan memperbaiki lingkungan tempat terkena banjir rob melalui kegiatan penanaman kembali mangrove atau bakau pada lahan kosong sekitar pesisir atau garis pantai. Oleh karenanya melalui kegiatan pengabdian terhadap masyarakat diharapkan kami tim pengabdi bisa mengajak masyarakat sekitar mau melakukan kegiatan penanaman kembali tanaman bakau atau mangrove dengan bantuan relawan mangrove dan para mahsiswa untuk mau membantu melakukan pengajakan atau penanaman kembali mangrove atau bakau pada lahan tersisa di sekitar garis pantai atau pesisir pantai wilayah DKI Jakarta.

\section{Metode Pelaksanaan}

Dalam mengenalkan permasalahan lingkungan khususnya mengenai dampak rob melalui kegiatan perkuliahan lapangan dan pengabdian masyarakat membentuk tim pengabdi yang terdiri dari dosen pembimbing sebagai penangung jawab kegiatan, kelompok pencinta pelestarian mangrove (Kemangteer) Jakarta dan beberapa perwakilan mahasiswa cinta lingkungan 
hidup. Peserta kegiatan mahasiswa pendidikan fisika semester 4 tahun ajaran 2018/2019 berjumlah 80 peserta dimaksudkan untuk melakukan perubahan dan perbaikan lingkungan disekitar wilayah pesisir Jakarta yakni di wilayah Pantai Indah Kapuk-Muara Angke, Jakarta Utara. Tempat kegiatan ini dilakukan pada wilayah Pantai Indah Kapuk-Muara Angke, Jakarta Utara. Kegiatan ini terbagi atas beberapa kegiatan, diantaranya: a) pengenalan mangrove dan bagaimana penanaman dan masa tumbuh dan perkembangnya. b) Pemaparan materi mengenai pasang air laut atau rob di laut Jakarta yang masuk pada wilayah garis pantai Jakarta, dampak dan permasalahan apabila lahan terbuka sekitar pantai sudah tidak ada. c) Kegiatan penanaman lahan terbuka sekitar Pantai Indah Kapuk-Muara Angke, Jakarta Utara.

\section{Hasil dan Pembahasan}

\section{Dalam melakukan pengabdian masyarakat dengan melakukan perubahan perbaikan lingkungan sekitar pantai Jakarta dan mengenalkan permasalahan lingkungan serta membentuk kelompok mahasiswa peduli lingkungan kami tim pengabdi melakukan beberapa langkah-langkah kegiatan yang telah dilakukan yakni:}

1. Pemaparan Materi Mengenai Tanaman Mangrove dan Air Pasang Laut Jakarta.

Pengenalan jenis mangrove, proses penanaman dan kesulitan mengembangkan dan menumbuhkan tanaman mangrove karena seringnya terkena pasang dan surut air laut Jakarta serta dampaknya. Kegiatan pemaparan materi pengenalan mangrove dan dampak dari berkurangnya lahan mangrove di Jakarta, sebagai narasumbernya adalah dari kelompok pecinta pelestarian mangrove (Kemangteer) Jakarta dan Departemen kehutanan dan lingkungan hidup DKI Jakarta. Kedua narasumber ini memaparkan mengenai kondisi lahan mangrove sekarang ini dengan kondisi lahan mangrove sebelum adanya pembangunan tempat tinggal dan pembangunan fasilitas umum lainnya. Pada masa sebelum adanya pembangunan fasilitas umum dan tempat tinggal yang masih belum banyak terutama pada pembangunan tempat tinggal sekarang ini, dimana masih luasnya lahan mangrove masih menyimpan banyaknya satwa khas lahan mangrove diantaranya banyaknya lutung jawa, monyet dan jenis ikan, udang yang hidup di rawa-rawa lahan mangrove. Namun lahan mangrove sekarang ini sudah menyempit dan luasnya makin sedikit apabila terjadinya pasang atau rob air laut Jakarta, lahan mangrove sudah tidak dapat menampung pasang air laut mengakibatkan terjadinya banjir pada wilayah sekitar pantai Jakarta khususnya pada wilayah Pantai Indah Kapuk-Muara Angke, Jakarta Utara. Memang beberapa titik sekitar Pantai Indah KapukMuara Angke, Jakarta Utara, sudah ditempatkan beberapa batu pembatas atau pemecah ombak agar apabila terjadinya pasang air laut Jakarta tidak dapat masuk kebeberapa wilayah sekitar pantai. Usaha itu tetap dilakukan namun tetap saja masih terkendala, banjir dari pasang air laut (rob) tetap terjadi.

Penanaman tanaman mangrove tetap dilakukan pada beberapa wilayah garis pantai Jakarta, namun terkendala kembali apabila pasang air laut Jakarta sedang naik tanaman mangrove yang sudah ditanam menjadi mati atau terbawa oleh ombak pasang air laut. Selain permasalahan tersebut tanaman mangrove untuk tumbuh besar membutuhkan waktu agak lama, bisa besar tanaman mangrove sekitar 5-7 tahun disebabkan karena tanaman endemik pada lahan rawa mengalami keasaman lahan tinggi mengakibatkan pertumbuhan lebih banyak pemanjangan akar dari pada batang mangrove untuk tumbuh keatas. Penanaman tanaman mangrove ini terus diperbaiki dengan terus melakukan pembibitan dan membuka lahan baru mangrove apabila wilayah sekitar pantai Jakarta mengalami menyusutan atau surut air laut.
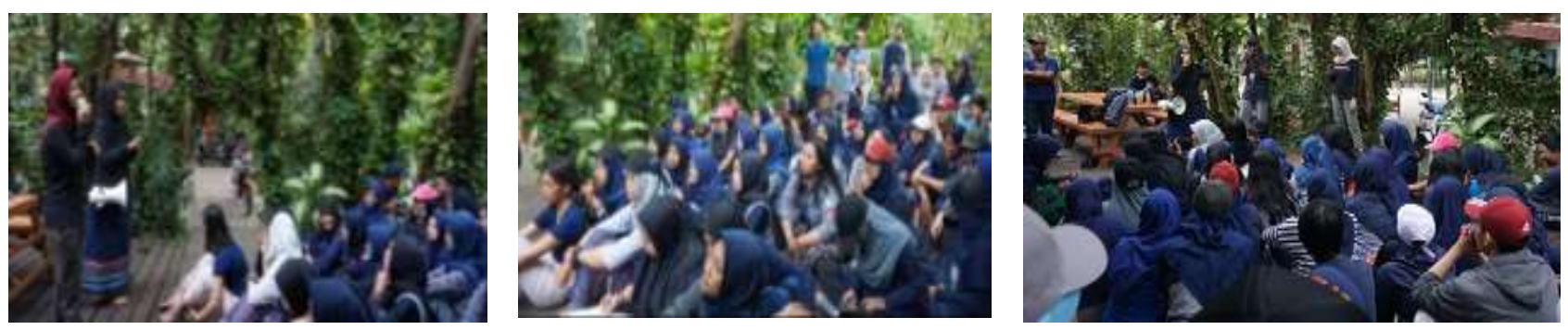

Gambar 1. Pemaparan Materi 
2. Kegiatan Penanaman Lahan Terbuka Sekitar Pantai Indah Kapuk-Muara Angke, Jakarta Utara.

Berdasarkan hasil pengamatan memang terlihat lahan mangrove sudah mengalami penyempitan dan tanaman mangrove pun jumlahnya sudah sedikit serta bibit yang sudah ditanam pun terkadang terbawa oleh pasang air laut jakarta atau terkadang busuk akar akibat beberapa kandungan lahan rawa mangrove terindikasi tercemar sampah dan kandungan senyawa lainnya. Kemungkinan cemaran ini disebabkan karena adanya penimbunan sampah anorganik sekitar lahan mangrove akibat aktivitas masyarakat dan industri.
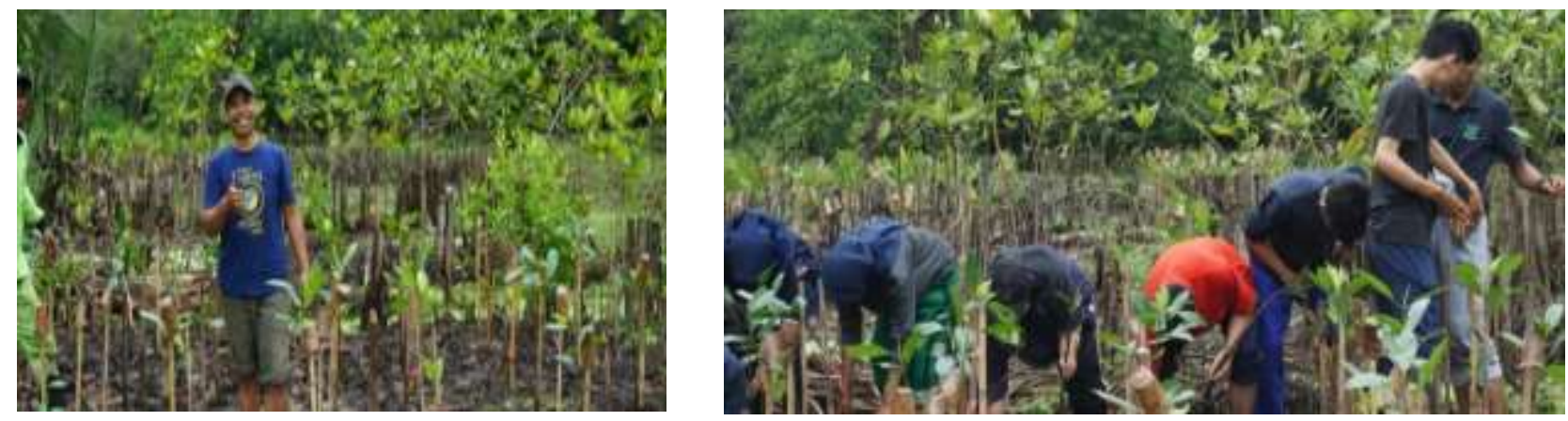

Gambar 2. Wilayah Penanaman Tanaman Mangrove

Kegiatan penanaman dilakukan sebagai tindakan bukti nyata mahasiswa peduli pada lingkungan khususnya pada wilayah sekitar pantai jakarta. Kegiatan penanaman tanaman mangrove pada lahan terbuka dibantu oleh petugas dinas kehutanan dan Lingkungan Hidup DKI Jakarta serta masyarakat. Kegiatan ini dilakukan untuk memberikan konsep dasar pengetahuan mahasiswa atas permasalahan yang sering terjadi di masyarakat sekitar khususnya masyarakat Pantai Indah KapukMuara Angke dalam menyelesaikan dan memberikan solusi dan upaya perbaikan terhadap lingkungan hidup. Kegiatan penanaman tanaman magrove memberikan pembelajaran kepada para mahasiswa bahwasannya luas lahan mangrove sekitar pesisir atau garis pantai jakarta sudah mengalami penyempitan dan keterbatasan lahan tebuka atau lahan mangrove mengakibatkan wilayah resapan air dan penahan pasang air laut atau rob sudah sedikit sekali berfungsi mengakibatkan kota jakarta mengalami banjir dan genangan air akibat pasang air laut atau rob jakarta. Peran kelompok mahasiswa ini diharapkan memberikan suatu perubahan positif terhadap lingkungan khususnya pada lahan mangrove sebagai upaya pencegahan banjir pasang air laut atau rob Jakarta.
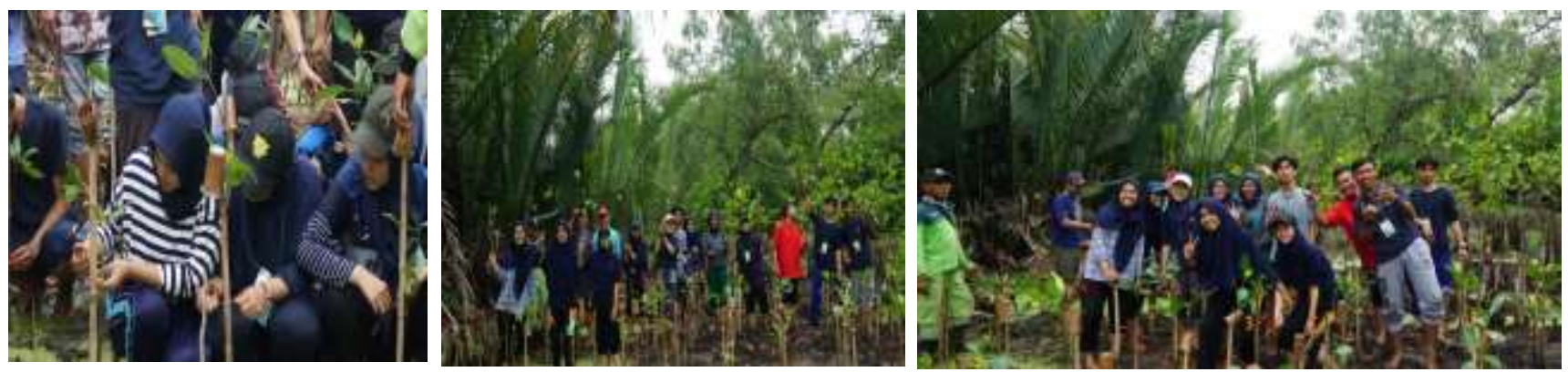

Gambar 3. Kegiatan Penanaman Oleh Kelompok Mahasiswa Peduli Mangrove

\section{Kesimpulan}

Berdasarkan hasil kegiatan yang telah dilakukan maka dapat disimpulkan bahwa: 1) Bahwasannya lahan mangrove diwilayah jakarta khususnya pada wilayah Pantai Indah KapukMuara Angke, Jakarta Utara sudah mengalami penyempitan yang mengakibatkan wilayah resapan dan penahan pasang air laut atau rob jakarta sudah mengalami fungsinya sedikit. 2) Dengan adanya kegiatan perkulihan lapangan dan pengabdian 
masyarakat diharapkan para mahasiswa memperoleh pengelaman langsung dan bisa menyelesaikan permasalahan yang terjadi di lingkungan sekitar. 3) Fungsi lahan mangrove sangat penting bagi kelestarian dan keanekaragaman rawa atau lahan mangrove.

\section{Ucapan Terima Kasih}

Kami Tim Pengabdi mengucapkan terima kasih kepada: 1) Kepala Prodi Pendidikan Fisika Univ. Indraprasta PGRI. Bapak Dasmo, M.Pd, 2) Ketua Kemangteer Jakarta, Saudari Nathasi, dan 3) Para Mahasiswa Pendidikan Fisika Universitas Indraprasta PGRI.

\section{Daftar Pustaka}

BPBD DKI Jakarta. (2017). Fenomena Banjir ROB. https://bpbd.jakarta.go.id/education/detail/10 $\underline{9}$

Nasution, N.B., Sayyidatul, K., Hasyim, A. (2018). Analisis Pengetahuan Awal Mahasiswa Mengenai Masalah Intrusi Air Laut Dan Rob. Jurnal Litbang Kota Pekalongan, Vol. 15 Tahun 2018.

Prawira, Medhiansyah Putra dan Adjie Pamungkas. 2014. Mitigasi Kawasan Rawan Banjir Rob di Kawasan Pantai Utara Surabaya. Jurnal Teknik POMITS, 3(2).

Sauda, R, H., Arief, L. N., Hani'ah. (2019). Kajian Pemetaan Kerentanan Banjir Rob Di Kabupaten Pekalongan.

Ubaidillah. 2010. Banjir Rob Jakarta. 3 Juni 2010 http://suarajakarta.co/opini/banjir-robjakartal 